\title{
2009 Pisacano Scholars
}

The Pisacano Leadership Foundation, the philanthropic arm of the American Board of Family Medicine, recently selected its 2009 Pisacano Scholars. These 5 medical students follow in the footsteps of 71 scholar alumni who are practicing physicians and 15 current scholars who are enrolled in family medicine residency programs across the country. The Pisacano Leadership Foundation was created in 1990 by the American Board of Family Medicine in tribute to its founder and first executive director, Nicholas J. Pisacano, MD (1924-1990). Each Pisacano Scholar has demonstrated the highest level of leadership, academic achievement, communication skills, community service, and character and integrity.

Bethany Enoch, a 2009 Pisacano Scholar, is a

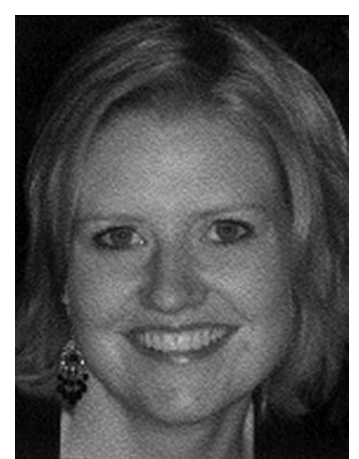

\section{Bethany Enoch}

fourth-year medical student at the University of Kansas School of Medicine. She graduated summa cum laude from MidAmerica Nazarene University with a Bachelor of Arts in Biology and Music Performance. As an undergraduate, Bethany received a number of honors and awards, including the President's Award, a half-tuition scholarship based on ACT scores. She also received the Phyllis M. Crocker Memorial Scholarship, awarded annually to outstanding music major students at MidAmerica Nazarene. In addition, she was chosen twice to perform in the school's Honor's Recital, a recital highlighting the best musical performances each semester. to receive numerous awards and has achieved significant leadership positions. At Kansas, she served as the president of the Family Medicine Interest Group and the vice president of the Kansas Alpha Omega Alpha chapter. Bethany also served as a student representative to the Kansas Academy of Family Physicians Board of Directors, and at the national level she was elected as the student chair of the American Academy of Family Physicians' National Conference of the Family Medicine Residents and Students. She previously served as a student representative to the Commission on Practice and Enhancement. Bethany has also volunteered with JayDoc, a student-run free clinic, since beginning medical school.

After moving to Kenya at the age of 10 with her parents who became missionaries and witnessing the disadvantages that so much of the world endures, Bethany decided in sixth grade that she wanted to become a doctor. At a very young age, she served children of AIDS victims who were living in orphanages and delivered food and blankets to victims of tribal violence near her school. Bethany is confident that her experience as a child is what led her to medical school. As a doctor, Bethany plans to provide full-spectrum care from delivering babies to providing end-of-life care. She plans to be active in her community and work for her patients by helping to implement healthy measures in the community.

Pamela Ferry, a 2009 Pisacano Scholar, is a
As a medical student, Bethany has continued

\section{Pamela Ferry}

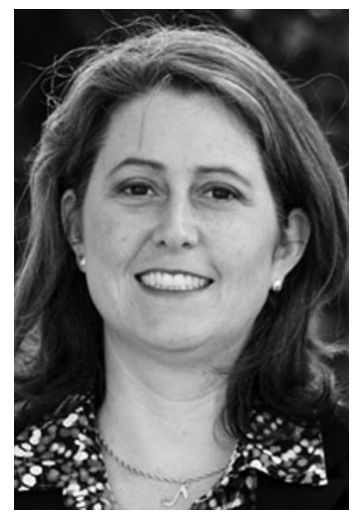

134 JABFM January-February 2010 Vol. 23 No. 1 
fourth-year medical student at Baylor College of Medicine. A National Merit Scholar, she graduated from Stanford University with a Bachelor of Arts in Human Biology. She also received a Master of Health Science with a major in International Health from Johns Hopkins University. As a Liberty Hyde Bailey fellow at Cornell University, Pamela completed doctoral coursework for her $\mathrm{PhD}$ before deciding to pursue her medical degree.

From 1992 to 1996, Pamela served as a missionary with the Mennonite Central Committee in Yapacani, Bolivia, working as a regional coordinator and health educator. During her 4 years there, she coordinated health promotion activities, including community health and nutrition education; training of community health promoters; water and sanitation projects; immunization campaigns; and agriculture and animal husbandry projects to improve economic and nutritional status. After returning from Bolivia, Pamela joined Baylor, where she is currently the assistant director for the Center for Educational Outreach and assistant professor of Allied Health Sciences. At Baylor, she oversees programs to increase access to medical careers for underrepresented college students, including enrichment experiences, mentoring, and educational research. Pamela was instrumental in the development of the Texas Joint Admission Medical Program (JAMP), which is now a well established state-wide program available to economically disadvantaged students.

During a brief hiatus from Baylor, Pamela spent 2 years directing a community-based breast cancer project for uninsured women. She has also volunteered with a number of organizations, including the Texas Children's Hospital and a teen girls' discipleship group at her local church. In addition, for the last 10 years Pamela has served as a team leader on annual mission trips to Montero, Bolivia. She organizes, leads, and translates for a team of medical professionals and volunteers who provide care to indigent families and a girls' orphanage. Last year, Pamela also participated in a medical mission trip to Riobamba, Ecuador. Most recently, Pamela received the DeBakey Scholar award from Baylor, which is awarded each year to a fourth-year medical student in honor of Dr. Michael E. DeBakey.

Pamela's professional goals include a commitment to advocacy and involvement in research on underserved care, international medical and public health work, and a patient-centered medical homemodel medical practice in an underserved population.

Anthony Lim, a 2009 Pisacano Scholar, is a

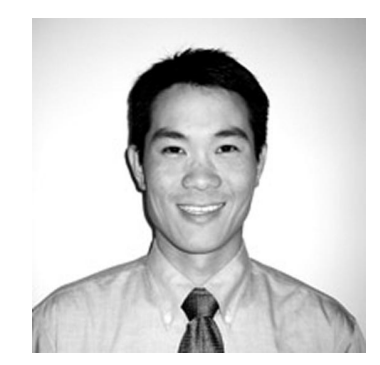

\section{Anthony Lim}

fourth-year medical student at Boston University School of Medicine (BU). He graduated Phi Beta Kappa and with distinction from Stanford University with a Bachelor of Arts in Human Biology. After graduation, he spent a year in Taiwan and China, fulfilling a lifelong dream to learn Mandarin. On returning to the United States, Anthony gained a year of valuable business experience working at a management consulting firm. He subsequently attended Harvard Law School, graduating with Cum Laude Honors. While at Harvard, he obtained certification as a mediator under Massachusetts law and worked as a mediator for the Harvard Mediation Program. He also worked as a summer law clerk at the San Diego Public Defender's office and as an intern with Health Law Advocates, where he provided legal counsel to low-income residents in Massachusetts who had been denied medically necessary services for insurance reasons.

Anthony was also the recipient of an AmeriCorps educational award for 1 year of public service within an underserved community. During this time, he taught math at a tuition-free middle school for children from economically disadvantaged families. Before attending medical school, Anthony spent a year as a clinical research assistant at the Joslin Diabetes Center, working on a nationwide National Institutes of Health study examining treatment options for type 2 diabetes in adolescents.

As a medical student at BU, Anthony has continued his commitment to service. Anthony was awarded a 2007-2008 Albert Schweitzer Fellow- 
ship. During his fellowship, he organized and led weekly therapeutic sessions for homeless individuals recovering from illness, and he co-organized and moderated a homeless symposium. He is currently participating in the selection process for this year's Schweitzer Fellows. Anthony also cofounded and coled BU's Christian Medical and Dental Association (CMDA). The organization has grown from 10 to more than 50 student members since its inception. Anthony was recently inducted into the Gold Humanism Honor Society, which honors medical students for "demonstrating excellence in clinical care, leadership, compassion, and dedication to service." In addition, Anthony participates in BU's Family Medicine Student Track, regularly participating in family medicine and primary care events, workshops, and meetings. Outside of school, Anthony enjoys hiking, bicycling, and spending time with his wife, Jean, and their 2-year old son, Joshua.

As a family physician, Anthony looks forward to a career that combines patient care, clinical teaching, and working with the underserved. He intends to work relentlessly at the individual, community, and policy-wide level toward building healthier communities.

Steven Lin, a 2009 Pisacano Scholar, is a

\section{Steven Lin}

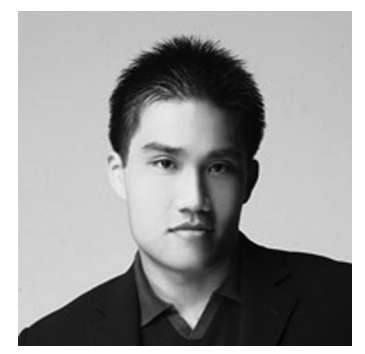

fourth-year medical student at Stanford School of Medicine. He graduated summa cum laude and Phi Beta Kappa from Duke University with a Bachelor of Science in Biology. His work on eliminating health inequities nationally made him the American Red Cross "Person of the Year" at Duke, where he was also elected chapter president. He received 3 major fellowships, including a Howard Hughes Medical Institute Award, for his research on creating cancer vaccines. For his academic and humanitarian accomplishments, he was named a national semifinalist for the Rhodes Scholarship.
At Stanford, Steven joined the Asian Liver Center, the first nonprofit organization in the country that addresses the disproportionate burden of hepatitis B and liver cancer in Asians. While spearheading outreach and educational projects both domestically and internationally in China, he conducted one of the largest epidemiologic studies of hepatitis B in Asian Americans, which won honors from the American College of Preventive Medicine and became a landmark paper in Hepatology. He was also a key contributor to the Asian Liver Center's "Physician's Guide to Hepatitis B"-an evidence-based practice guideline funded by the Centers for Disease Control and Prevention, now used by health departments across the country to educate their doctors and serve their communities. Later, he joined the Steering Committee for San Francisco Hep B Free, a citywide campaign to turn San Francisco into the first hepatitis B-free city in the nation. Working with the Department of Public Health and the California State Assembly, he helped create public and provider awareness about the importance of routine hepatitis $B$ testing and vaccination and ensuring access to treatment for chronically infected individuals, especially for those who are unable to pay. During this time, he gave over a dozen presentations at major national conferences.

Next, Steven received the Albert Schweitzer Fellowship to start a free clinic for underserved Asians at risk for hepatitis B and liver cancer. In 1 year, the clinic served more than 500 uninsured immigrants with no access to care and identified nearly 100 individuals with chronic hepatitis B or liver cancer. His clinic attracted national media attention and was inducted into the National Task Force on Hepatitis B. In recognition of his work, Steven was awarded the American Academy of Family Physicians' Student Community Outreach Award.

Karl Metzger, a 2009 Pisacano Scholar, is a

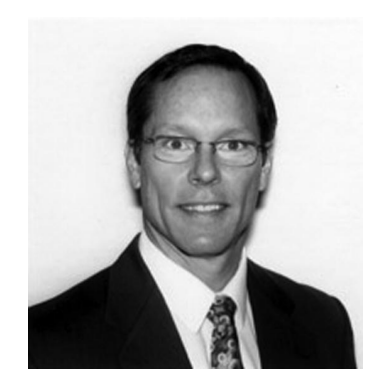

Karl Metzger 
fourth-year medical student at the University of Kansas School of Medicine. He graduated from the University of Nebraska - Lincoln with a Bachelor of Science in mechanical engineering. While attending night school to obtain his undergraduate degree, Karl also began his 20-year career in the engineering field. During his engineering career, he put close to two dozen products on the market and earned 2 separate patents. During this time, he also joined the US Marine Corps Reserve and continued to serve 6 years in the reserves. He was awarded the Meritorious Mast for Leadership for outstanding leadership as a Programming Team Leader.

Karl's management experience in his engineering career subsequently led to a new career as the business manager of large health club. Here, Karl discovered his passion for helping others, which subsequently ignited his desire to enter medical school. As a medical student, Karl has continued his leadership and academic excellence. During his first 2 years of medical school, he participated in the Kansas University Medical Center International Outreach's (KUMCIO) medical mission trip to Belize. He served as the assistant to the trip leader his first year and as the trip leader for both trips the following year. He described his experience on these trips as not only enriching and rewarding but also as one which anchored his commitment to Family Medicine. Karl also served as the project director for the Kansas University Medical Center Community Health Project, which places secondyear medical students in community safety net clinics. He comanaged the placements of the students and monitored their experiences with the community organizations. In addition, Karl has also volunteered with the JayDoc student-run free clinic since his first year of medical school.

Karl describes himself by the priorities in his life. First is his deep sense of spirituality which gives him the strength and peace to be effective in the rest of his life; next is his commitment as a husband, a father, and a son; following that is his dedication to becoming a physician; and lastly are his own interests such as martial arts and Ironman triathlete events.

After residency, Karl envisions his future career in an integrated practice that offers a variety of services in both conventional and complementary medicine as well as small groups, social/community support, psychiatry, counseling, exercise, and nutrition. He also plans to volunteer for the underserved both nationally and internationally.

Jane Ireland American Board of Family Medicine 